\title{
Incontinentia pigmenti: the development of pseudoglioma
}

\author{
C A BROWN \\ From Bristol Eye Hospital and Southmead Hospital, Bristol
}

SUMmary A case is described of incontinentia pigmenti in an infant with relatively normal retinae at seven days after birth who went on to total blindness by three months. This was due to excessive neovascularisation of retinae and vitreous, leading to bilateral pseudoglioma.

Incontinentia pigmenti (Bloch-Sulzberger syndrome) is a generalised ectodermal and mesodermal dysplasia affecting eyes, skin, hair, nails, teeth, bones, and central nervous system. It nearly always affects females. It appears at or very soon after birth. The skin lesions start as a generalised blistering rash with vesicles or bullae on trunk and limbs. These heal and leave typical pigmented lines and whorls and sometimes verrucous lesions. The pigment comes from melanin granules which migrate from the epidermis into the dermis, where they are either free or absorbed by chromatophores.

The disease causes blindness, total or partial, in $25 \%$ to $35 \%$ of cases. ${ }^{1}$ This paper describes the condition from one week after birth to the fully developed pseudoglioma.

\section{Case history}

A girl, a first baby, was born at 41 weeks gestation, birth weight $3 \cdot 1 \mathrm{~kg}$. Both parents were normal and there was no consanguinity. At 8 hours after birth she developed a generalised blistering rash suggestive of incontinentia pigmenti. At age 3 days she had twitching of her right arm and leg. Her skin progressed through the typical changes of incontinentia pigmenti, with linear pigmented lines on the trunk and the limbs and some verrucous lesions. The diagnosis was confirmed by biopsy.

At age 1 week (first ocular examination) the fundi showed dilated retinal veins in both eyes, with a small area of neovascularisation and exudates along the course of the left superior temporal retinal artery and vein above the macula (Fig. 1).

Correspondence to Mr C A Brown, Combe House, Redhill, Bristol BS18 7SH.
At 5 weeks the irides were vascularised. The retinal veins were now grossly dilated $(\times 3)$ and tortuous, and there was extensive neovascularisation and oedema round the discs and the posterior pole (Figs. 2 and 3), but there was very little neovascularisation in the peripheries.

At 10 weeks there was increased vascularisation of the irides. The neovascularisation of the retinae and vitreous had massively increased, with vitreous haze and fibrosis in both eyes (Fig. 4).

At 13 weeks the vitreous haze had increased so that there was only a temporal red reflex in the right eye and no red reflex in the left. The retrolental membranes were almost total in the right eye and total in the left. The picture was now that of bilateral pseudoglioma.

Treatment was attempted with small doses of ACTH (5 units alternate days) from 2 to 5 months of age, but this was without any effect.

The child continued to have gross mental retardation, spasticity, and fits, and was totally blind, with bilateral retrolental membranes and a secondary cataract in the left eye.

\section{Discussion}

Incontinentia pigmenti was first described by $\mathrm{Bloch}^{2}$ and Sulzberger. ${ }^{3}$ In 1976 Carney' $^{\prime}$ found 464 references in the world literature, including 653 valid case reports. The skin lesions occur in all cases, and have been outlined above. Abnormalities of the central nervous system occur in over $30 \%^{1}$ and include epilepsy, spasticity, mental retardation, microcephaly, and hydrocephaly.

Dental abnormalities are seen in $65 \%$ of cases. ${ }^{1}$ Some teeth are absent, others being pegged and malformed. Abnormalities of bone occur in more 


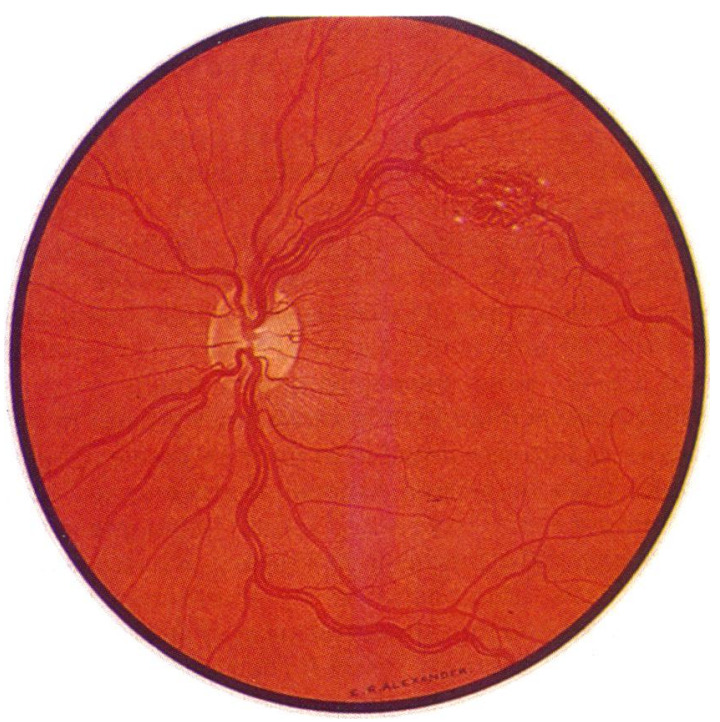

Fig. 1 Left fundus at age 1 week, showing dilated retinal veins and one area of neovascularisation and exudates.

than $20 \%$ of cases (skull deformities, kyphoscoliosis) and other congenital abnormalities (dwarfism, cleft palate, etc.) in $14 \%$.

The ocular abnormalities are among the most important. Findlay ${ }^{4}$ found an incidence of $32 \%$, Scott et al. ${ }^{5}$ found $26 \%$, and Carney' found $18.9 \%$ with serious visual defects and $15 \%$ with milder defects.

The serious ones are pseudoglioma, retinal detach-

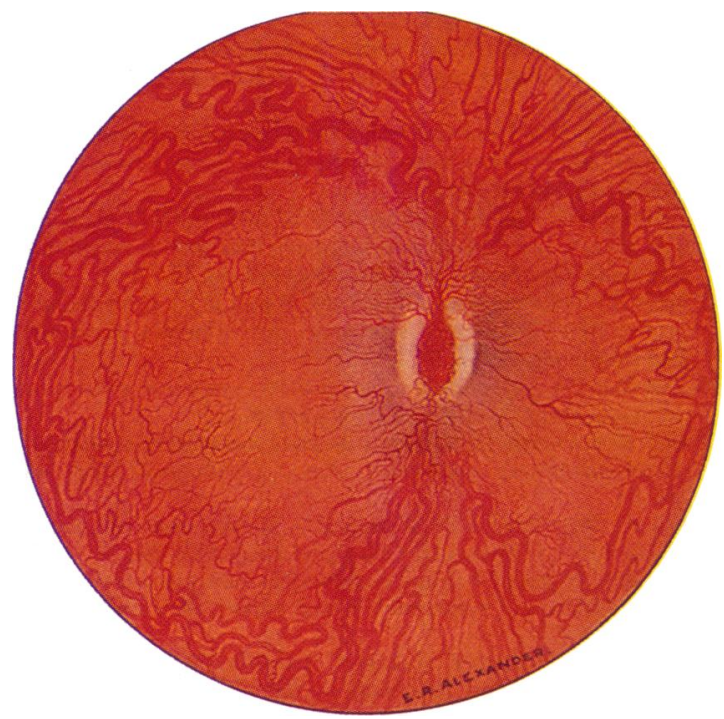

Fig. 2 Right fundus at age 5 weeks, showing dilated tortuous retinal vessels and neovascularisation of disc and retina.

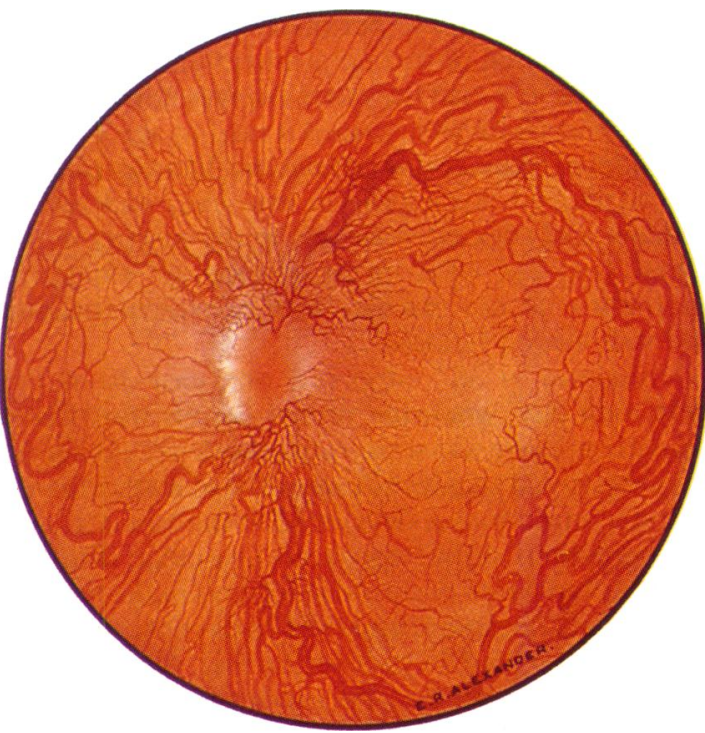

Fig. 3 Left fundus at age 5 weeks, showing dilated tortuous retinal vessels and neovascularisation of disc and retina.

ment, optic atrophy, cataract, microphthalmos, and phthisis bulbi. ${ }^{46}$ The milder changes include exudative choroiditis, ${ }^{7}$ peripheral retinal changes, ${ }^{8-10}$ nystagmus, strabismus, and myopia.

The early retinal changes have been described by Findlay, ${ }^{4}$ Lieb and Guerry, ${ }^{7}$ and Nishimura et al. ${ }^{10}$ Findlay described a case at age 2 months with dilated retinal and choroidal vessels in one eye and a greyish

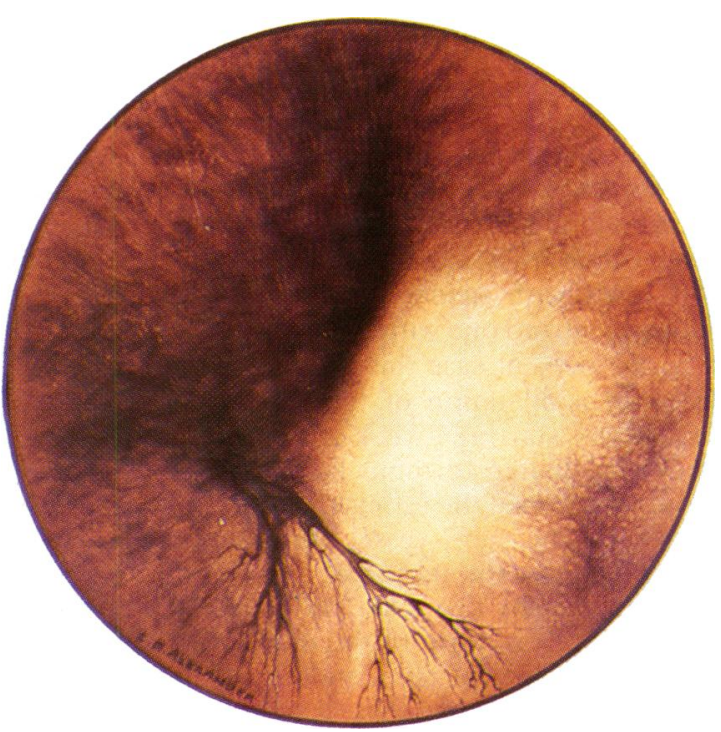

Fig. 4 At age 10 weeks an ophthalmoscopic view of the left vitreous showing neovascularisation and fibrosis. 
retinal elevation in the periphery. At 6 months this baby had a nasal retinal detachment and retrolental mass in that eye, and the other eye was normal.

Lieb and Guerry described a case at age 4 weeks with dilated retinal veins and pannus-like vascularisation at the posterior pole in one eye, and retinal oedema and corkscrew vessels at the macula in the other. One eye went on to develop an 'exudative choroiditis' at the macula, with neovascularisation and star-shaped exudates.

Nishimura et al. ${ }^{10}$ observed one case from the thirteenth day, when the retinal vessels were fairly normal but there was some retinal oedema. At age 34 days the retinal venules became dilated and tortuous, vascular anastomoses developed at the equator, and the peripheral retina appeared avascular. Further neovascularisation occurred at 62 days in the left eye but the right became normal. At 78 days photocoagulation was applied to prevent further vascular proliferation in the left eye. At 1 year the right eye was comparatively normal but in the left there was optic atrophy and pigmentary degeneration at the macula and general constriction of the retinal vessels.

These three cases showed early changes similar to the one described here but they were less severe and only one ${ }^{4}$ went on to develop a partial pseudoglioma.

Later retinal changes were described by Watzke $e t$ al. ${ }^{8}$ In 19 cases all over the age of 2 years they found five with unilateral and two with bilateral zones of abnormal arteriovenous anastomoses and preretinal fibrosis at the temporal equator, and no retinal perfusion temporal to it. Jain and Willetts ${ }^{9}$ described a case in a girl who had had incontinentia pigmenti from birth and at the age of 14 years had microaneurysms temporal to the macula and retinitis proliferans in the upper temporal equator.

Other retinal changes include abnormalities of the pigment epithelium, glial strands, haemorrhagic and pigmentary retinitis, retinal dysplasia, and retinal detachment. François" surveyed the literature of retinal changes in incontinentia pigmenti and added two cases with ocular changes, one with retinal detachment and one with optic atrophy and squint.

In the present case the pathological process consisted of a dilatation of the retinal and choroidal circulations starting 1 week after birth, followed at 5 weeks by dilated tortuous retinal vessels and neovascularisation of the retina and disc in both eyes. By 10 weeks the new vessel formation had spread forwards into the vitreous, leading to bilateral pseudoglioma by 13 weeks. The child had the general signs of a severe form of the disease with extensive ocular, neurological, skin, and dental involvement.

Watzke et al. ${ }^{8}$ state that 'it may be that pseudoglioma is the end stage of this retinal vascular abnormality'. Similarly François" ${ }^{11}$ states that 'pseudoglioma is probably the end stage of the retinal vascular changes'. The case described here is proof of this sequel of events.

The cause of the vascularisation remains obscure. In recent work on kittens' retinae Taylor et al. ${ }^{12}$ think they may have isolated the metabolite that stimulates new vessel formation in the eye, postulated by workers over the last 40 years. ${ }^{13}$ They suggest that vascularisation may be stimulated by endothelial-cell stimulating angiogenic factor (ESAF). They found that ESAF, when measured quantitatively by procollagenase activation, was three times greater in the retinae of kittens subjected to prior excessive oxygen intake than in normal kittens. Watzke et al. ${ }^{8}$ and Nishimura et al. ${ }^{10}$ have noted retinal ischaemia in the periphery of the fundus with absence of perfusion in these areas (demonstrated by fluorescein angiography) beyond the equatorial areas of arteriovenous anastomoses and new vessel formation. This retinal ischaemia may well be the source of the angiogenic factor ESAF in this disease, and so be the cause of the extensive neovascularisation observed in this case in both the retinae and the irides, possibly following prior retinal ischaemia. Further research work along these lines may lead to advances in understanding and treating the ocular complications of incontinentia pigmenti.

I wish to thank Dr Beryl Corner and Dr Roger Harman, of Southmead Hospital, Bristol for referring this case, and Mr E R Alexander for the fundus paintings.

\section{References}

1 Carney RG. Incontinentia pigmenti. A world statistical analysis. Arch Dermatol 1976; 112: 535-42.

2 Bloch B. Eigentümliche, bisher nicht beschriebene Pigmentaffektion (incontinentia pigmenti). Schweiz Med Wochenschr 1926; 56: 404.

3 Sulzberger MB. Über eine bisher nicht beschriebene congenitale Pigmentanomalie (incontinentia pigmenti). Arch Dermatol Syph (Berlin) 1928; 154: 19-32.

4 Findlay GH. On the pathogenesis of incontinentia pigmenti, with observations on an associated eye disturbance resembling retrolental fibroplasia. BrJ Dermatol 1952; 64: 141-6.

5 Scott JG, Friedmann AJ, Chitters M, Pepler WJ. Ocular changes in the Bloch-Sulzberger syndrome (incontinentia pigmenti). Br J Ophthalmol 1955; 39: 276-82.

6 Zweifach PH. Incontinentia pigmenti. Its association with retinal dysplasia. Am J Ophthalmol 1966; 62: 716-2.

7 Lieb WA, Guerry D. Fundus changes in incontinentia pigmenti. (Bloch-Sulzberger syndrome). Am J Ophthalmol 1958; 45: 265-71.

8 Watzke RC, Stevens TS, Carney RG. Retinal vascular changes of incontinentia pigmenti. Arch Ophthalmol 1976; 94: 743-6.

9 Jain RB, Willetts GS. Fundus changes in incontinentia pigmenti (Bloch-Sulzberger syndrome): a case report. Br J Ophthalmol 1978; 62: 622-6.

10 Nishimura M, Oka Y, Takagi I, Yamana T, Kitano A. The clinical features and treatment of the retinopathy of BlochSulzberger syndrome (incontinentia pigmenti). Jpn J Ophthalmol 1980; 24: 310-9.

11 François J. Incontinentia pigmenti (Bloch-Sulzberger syndrome) and retinal changes. Br J Ophthalmol 1984; 68: 19-25. 
12 Taylor CM, Weiss JB, Kissun RD, Garner A. Effect of oxygen tension on the quantities of procollagenase-activating angiogenic factor present in the developing kitten retina. Br J Ophthalmol 1986; 70: $162-5$
13 Anonymous. Neovascularisation (Editorial). Br J Ophthalmol 1986; 70: 161 .

Accepted for publication 23 April 1987. 